\title{
Editorial: On Academic Generosity
}

\author{
Gert Biesta
}

Published online: 10 December 2013

(C) Springer Science+Business Media Dordrecht 2013

There can be no doubt that academic publishing is nowadays closely intertwined with global capitalism (see for example McGuigan \& Russell 2008; Phillips 2009; Biesta 2012). This is first of all because major publishers of academic journals and books are global companies with wide and deep networks all over the world. But it is also because the 'logic' of academic publishing itself is increasingly becoming a matter of the production of intellectual commodities - articles and chapters - with the aim of establishing a position in the academic market (known as 'impact'). The transformation of academic activity into a process of the production of intellectual commodities is further exacerbated by funding regimes that reward quantity over quality-such as in those cases where universities, departments, or even individual scholars get paid directly for each publication they produce. ${ }^{1}$ Recent developments with regard to open access (Willinsky 2006) are beginning to change the publishing landscape (see Laakso et al. 2011), yet in many fields the role of commercial publishers as the main distributors of and the main gateways into research remains strong.

The current situation is of course the outcome of particular historical developments, and such developments are never without contradiction and irony. Perhaps the greatest irony lies in the fact that the publishing industry strongly relies on the willingness of academics to make their work available for free-with publication of their work as the only 'reward' - and also on the willingness of academics to conduct peer review of manuscripts so as to safeguard the quality of the 'product' commercial publishers are selling. One could look at this just from a cynical perspective and conclude that the contribution of academics

\footnotetext{
${ }^{1}$ Unlike what scholars in other countries often seem to think, the UK is an interesting exception to this, as its main mechanism for the allocation of research funding focuses on an evaluation of the quality of a maximum of 4 publications per scholar over a selected period of time-usually about 6 or 7 years (see http://www.ref.ac.uk for the most recent framework used for research evaluation in the UK).
}

G. Biesta $(\bowtie)$

Institute of Education and Society, Faculty of Language and Literature, Humanities, Arts and Education, University of Luxembourg, Campus Walferdange, Route de Diekirch, BP2, 7220 Walferdange, Luxembourg e-mail: gert.biesta@uni.lu 
to commercial publishing is a form of modern slavery; or, to put it in less extreme but nonetheless serious terms: that what is happening is the transformation of the public monies that pay for academics' salaries into the private profits of commercial publishers and the global conglomerates of which they are part. This is of course true, and one could therefore well argue that particularly in 'high stakes' areas of research and scholarshipsuch as, for example, medicine and engineering-authors and reviewers should be adequately compensated for their efforts.

In less 'high stakes' areas such as the theory and philosophy of education, these issues also play a role, but whereas in high stakes areas the first purpose of peer review is to assess whether the claims made are sound and sufficiently robust-after all, lives ultimately depend on them - the function of peer review in fields such as the theory and philosophy of education seems to me to be a slightly different one. While the ultimate task of reviewers here is to assess the quality of a manuscript-for example with regard to questions about the strength of the argumentation and the extent to which existing literature on the topic has been adequately and accurately represented - the review process also has a strong formative dimension and is, in that regard, often more dialogical than judgemental. Many authors can testify that their manuscript has often significantly improved as a result of feedback received from reviewers, and from my perspective as editor in can often see in much detail how manuscripts can grow, deepen, and even completely transform as a result of the reviewing process. All this crucially depends on the generosity of reviewers, that is, on their willingness to offer their time, attention and expertise. While we could say that they are just duped into filling the coffers of the global publishing industry-which of course is also true-we should nonetheless not forget that these generous contributions have a significant impact on the quality of the scholarship in our field as a whole, and also on the careers of individual scholars.

That is why I also think that authors should be generous in acknowledging the contributions reviewers (and to a very small extent perhaps also editors) make to their work and the quality of the scholarship in the field more generally-reviewers as the silent or invisible co-authors of much of what is being published. My impression is that this is not really part of the publishing culture in our field-and perhaps it is not really part of the culture of academic publishing more generally. I find this unfortunate, and this is the main reason why authors publishing in this journal will increasingly find me providing them with an opportunity, in the penultimate stage of the process towards publication, to acknowledge the contributions reviewers have made to their paper. While we cannot deny that as academics we are caught up in complex and often contradictory networks, we should not lose sight of the wider significance of our work, and we should be generous in acknowledging the contributions of all who make this possible.

It is also with this in mind that I would like to express my sincere gratitude to Ann Chinnery who since 2008 has been responsible for the book reviews section of Studies in Philosophy and Education. Studies has a unique tradition of review essays and rejoinders, and Ann has made a major contribution in continuing this tradition through a fine selection of books and, most importantly, reviewers. Given that in the hierarchy of academic production book reviews have a pretty low status, it is even more remarkable that Ann has continued to engage a wide range of colleagues in serious engagement with recently published books in our field. I am grateful to Ann for her contribution to the journal and the field. And I am also extremely grateful that Samuel Rocha has agreed to take over from Ann in this important role. I wish him all the best with this task and hope that many colleagues in the field will-generously_-support him. 


\section{References}

Biesta, G. J. J. (2012). Knowledge/democracy. Notes on the political economy of academic publishing. International Journal of Leadership in Education, 15(4), 407-420.

Laakso, M., Welling, P., Bukvova, H., Nyman, L., Björk, B.-C., et al. (2011). The development of open access journal publishing from 1993 to 2009. PLOS ONE, 6(6), e20961. doi:10.1371/journal.pone. 0020961.

McGuigan, G. S., \& Russell, R. D. (2008). The business of academic publishing: A strategic analysis of the academic journal publishing industry and its impact on the future of scholarly publishing. Electronic Journal of Academic and Special Librarianship 9(3). http://southernlibrarianship.icaap.org/content/ v09n03/mcguigan_g01.html (accessed 30 June 2012).

Phillips, A. (2009). Business models in journals publishing. In B. Cope \& A. Phillips (Eds.), The future of the academic journal. Oxford: Chandos.

Willinsky, J. (2006). The access principle: The case for open research and scholarship. Cambridge, MA: MIT Press. 